\title{
Females' esophagus cancer incidence in Golestan Province, Iran (2004)
}

\author{
Dr. Abdoljalal Marjani ${ }^{*}$ PhD, Mr. Mohammad Javad Kabir ${ }^{* *}$, Dr. Shahriyar \\ Semnani MD ${ }^{* * *}$, Dr. Seyyed Mehdi Sedaghat ${ }^{\dagger}$, and Mr. Abbas Moghaddami ${ }^{\dagger \dagger}$ \\ *Dept. of Biochemistry \& Biophysics, Golestan University of Medical sciences, Iran \\ **Department of Social Medicine, Golestan University of Medical sciences, Iran \\ *** Department of Endocrinology, Golestan University of Medical sciences, Iran \\ ${ }^{\dagger}$ Department of Disease control in Golestan Health Deputy, Iran \\ ${ }^{\dagger \dagger}$ Department of cancer registry in Golestan Health Deputy, Iran
}

\author{
(Received 26 October 2007 and accepted 23 November 2007)
}

\begin{abstract}
Esophagus cancer is one of the most common cancers in women and therefore represents a major problem in public health. The main aim of this study was to find and describe province-specific estimates of incidence in females by age groups for esophagus cancer. The data used in this study were collected in a cancer registry that was conducted by Health Deputy of Golestan province for a period of 1 year (2004). The age distribution was collected according to the following age strata: 0-4, 5-9, 10-14, 15-19, 20-24, 25-29, 30-34, 35$39,40-44,45-49,50-54,55-59,60-64,65-69,70-74,75-79,80-84$ and 85 above. Esophagus cancer data was identified and collected through the 18 Pathology Laboratory centers (where female populations were referred to these centers) in Golestan province. A total of 348 primary cancer cases were captured. From these 32 cases were of esophagus cancer. There were 26 cases of squamous cell carcinoma $(81.25 \%)$, and 1 adenocarcinoma (3.12\%). Esophagus cancer incidence among females in Golestan province was 7.62/100000. But esophagus cancer with the highest ASR: 127.91/100,000 was in age 75-79. The incidence of esophagus cancer in age over 75-79 has risen sharply and it was the lowest in age 30-34 (ASR: 1.68/100,000). Presently it can be said that esophagus cancer in females appears to be one of the most prevalent and serious types of cancer (especially squamous cell carcinoma) in Golestan province and esophagus cancer is rising with ageing.
\end{abstract}

KEY WORDS: Esophagus cancer; Incidence; Female; Agestandardized rates (ASR)

\section{INTRODUCTION}

Cancer is becoming a leading cause of death in many countries of the world. In 1984, over half of the annual world total of 5.8 million new cancer cases was reported from developing countries $^{1}$. Many studies demonstrate that cancer incidence among different people are heterogeneous. Esophageal cancer is the sixth most common cause of cancer mortality worldwide. The incidence of this disease shows a striking geographic variation in the world; a 20 fold variation is observed between high-risk
China and low-risk western Africa ${ }^{2}$. Geographic variability is even more marked when smaller units are studied; for example, when comparisons are made among countries or even within countries. It seems that the environmental carcinogens responsible show important geographic differences ${ }^{3}$. In Europe and North America, 90\% of esophageal cancer is caused by tobacco plus alcohol. In the high risk countries of South America, hot beverages, particularly hot mate are important ${ }^{4}$.

(Corresponding Author: Dr. Abdoljalal Marjani, Associate Professor, Department of Biochemistry \& Biophysics, Golestan University of Medical sciences, Gorgan, Iran, Email: abdoljalal@yahoo.com) 
Esophageal cancer is one of the most common malignant tumors with a high incidence in such regions as China, Iran, South Africa, Uruguay, France and Italy ${ }^{5}$. Some of the highest rates occur in northern China and northern Iran, where incidence exceeds 100 in 100,000 individuals; in the U.S., the incidence is less than 5 per 100,000, although rates are nearly quadruple for African Americans ${ }^{6}$. Annually, it is estimated that 15,560 Americans will be diagnosed with esophageal cancer, and 13,940 will die of this malignancy. Of the new cases, it is estimated that 12,130 will occur in men and 3,430 will occur in women ${ }^{7}$. Iran is one of the known areas with a high incidence of esophageal cancer. Most of the patients in Iran have been reported from the north and northeast regions of the country. In one survey by the Iran Cancer Institute, 9\% of all cancers and $27 \%$ of gastrointestinal cancers were esophageal carcinoma. The male to female ratio was $1.7 / 1^{8}$. A recent report from Ministry of Health shows that more than $70 \%$ of deaths are caused by cardiovascular diseases, injuries and cancers, while fewer than $3 \%$ of deaths are the consequence of infectious or parasitic diseases. Therefore understanding and quantifying the burden of cancer as one of the three major causes of death in the country is essential ${ }^{9}$. Study of cancer cases in this region during the 1996-2000 period showed that Age-standardized rates (ASR) for esophageal cancer in females was $36.3 / 100000^{\mathbf{1 0}}$. In 2002 and 2003 two separate reports of population based cancer registries were published from Iran. These reports showed that Age-standardized rates (ASR) for esophageal cancer in females was $14.4 / 100000^{11}$. The main aim of this study was to find and describe province-specific estimates of incidence by age groups for esophagus cancer in the year 2004.

\section{MATERIALS AND METHODS}

The data used in this study were collected in a cancer registry that was conducted by Health Deputy of Golestan province in Iran for a period of 1 year (2004). This article focuses on female cancer registry. Golestan province is located in north of Iran (South East of Caspian Sea). The collected data included population distribution by gender (female) and age, divided into fiveyear intervals. The age distribution was collected according to the following age strata: 0-4, 5-9, $10-14,15-19,20-24,25-29,30-34,35-39,40-44$, 45-49, 50-54, 55-59, 60-64, 65-69, 70-74, 75-79, 80-84 and 85 above. Different cancer data was identified and collected through the 18 Pathology Laboratory centers (where male populations referred to these centers) and using a structured questionnaire, trained personnel conducted inperson interviews to collect information on esophagus cancer in the Golestan province. The newly diagnosed cases detected by histopathological, cytological examinations. These were then sent to the Cancer Registry Office of the province and to the registry unit in the Health Deputy. Age-specific rates, annual age-adjusted rates (ASRs) per 100,000 personyears were calculated using the direct methods of standardization to the world population. The data were summarized in a data sheet and coded using the ICD-O. The data were recorded at different levels due to a need for correct registration. This has been done by iarccrgtools-203 software.

\section{RESULTS}

A total of 348 cases with cancer from all sites were captured during the one year period, 2004. From these, $32(9.20 \%)$ cases were of females' esophagus cancer. There were 26 cases of squamous cell carcinoma $(81.25 \%)$, and 1 adenocarcinoma $(3.12 \%)$ The incidence for squamous cell carcinoma was the highest in Golestan province. The results from Golestan province Cancer Registry for the year period 2004 show that cancer of esophagus is the second common cancer of women. The Annual Specific Rate (ASR) is 7.62 per 100,000 in females. The highest esophagus cancer incidence among females in Golestan province was in age 75-79 (ASR: 127.91/100,000). The incidence of esophagus cancer in age 75-79 has risen sharply and in age 30-34 it was the lowest. The esophagus cancer incidence according to age specific is shown in table 1 . 
Table 1: Esophagus cancer incidence among females in Golestan province in 2004

\begin{tabular}{|c|c|c|}
\hline $\begin{array}{c}\text { Age Group } \\
\text { (Years) }\end{array}$ & Persons & $\begin{array}{c}\text { Incidence } \\
\text { Rates } \\
\text { (Per 100,000) }\end{array}$ \\
\hline $0-4$ & 69465 & -- \\
\hline $5-9$ & 84583 & -- \\
\hline $10-14$ & 112921 & -- \\
\hline $15-19$ & 123107 & -- \\
\hline $20-24$ & 89519 & -- \\
\hline $25-29$ & 67719 & -- \\
\hline $30-34$ & 59689 & 1.68 \\
\hline $35-39$ & 52192 & 1.92 \\
\hline $40-44$ & 35723 & 2.80 \\
\hline $45-49$ & 29885 & 3.35 \\
\hline $50-54$ & 28116 & 17.78 \\
\hline $55-59$ & 21321 & 14.07 \\
\hline $60-64$ & 13615 & 36.72 \\
\hline $65-69$ & 8240 & 46.54 \\
\hline $70-74$ & 8614 & 46.44 \\
\hline $75-79$ & 3909 & 127.91 \\
\hline $80-84$ & 2923 & 34.21 \\
\hline Above 85 & 1818 & 55.01 \\
\hline
\end{tabular}

\section{DISCUSSION}

Esophagus cancer is a relatively rare form of cancer, but some world areas have a markedly higher incidence than others: China, India and Japan, as well as the United Kingdom, appear to have a higher incidence, as well as the region around the Caspian Sea. Annual incidence is between 0.6-6 per 100,000 for females ${ }^{12}$. The findings of this study showed that esophagus cancer is one of the most common cancers in the Golestan province among females. The registry showed that the annual ASR for esophagus cancer was 7.62 per 100000 populations among females (the second common cancer). Comparison of the ASR for esophagus cancer among females in Golestan province with those of esophagus cancer worldwide show that the Golestan province is lower-risk areas than other places. The incidence of esophagus cancer rises from age 30 years old and is highest in age 75-79 years old. There are many factors for incidence of esophagus cancer. Diet certainly plays an important role. Risk is increased by high intake of some traditionally preserved salted foods, especially salted fishes and cucumber. Risk is probably increased with the use of pesticide in agricultural products in this area such as some cucumber, tomatoes, strawberry etc., using deposed wheat and corn contaminated with aflatoxin, hot tea drinking habit, change in lifestyle, the high caloric and fatty diet intake. Risk is decreased by high intake of fruits and vegetables which may be in part related to their vitamins $\mathrm{A}, \mathrm{C}$ and $\mathrm{E}$ content ${ }^{13}$. Excessive use of tobacco and alcohol has clearly been shown to be a risk factor for esophagus cancer ${ }^{14}$. In fact, it is estimated that $90 \%$ or more of the risk of esophageal cancer in Western Europe and North America can be attributed to tobacco and alcohol ${ }^{3}$. The incidence of esophageal cancer in the Golestan province was lower when compared with other places in the world, which may be related to the relatively low consumption of alcohol in the region. The increasing consumption of cigarettes smoking has also been clearly accepted as increasing the risk of esophagus cancer ${ }^{15}$. Compared with the data of $1999-2000^{10}, 2002$ and $2003^{11}$ the incidence of esophageal cancer is much lower. This decrease can be attributed to better economic status, and personal health, better nutrition, and changing in high-risk behavior ${ }^{16-17}$. Clinicians should follow recommended screening guidelines and encourage their patients before age 30 and older (in this area). Clinicians should also ensure that patients at high risk for esophagus cancer are identified and offered appropriate referrals and treatment.

\section{CONCLUSION}

Continued research is needed on the causes, prevention, and treatment of esophageal cancer. The age specific esophagus cancer among females may be the second cause of cancer deaths (after breast cancer) in Golestan province. For the present time it can be said that esophagus cancer (especially squamous cell carcinoma) in females appear to be one of the most prevalent and serious type of cancer after stomach cancer in Golestan province and is rising with age. Thoughtfully designed epidemiological and clinical studies are pivotal to unravel the details of why and how these are happening and help to plan what should be done to combat effectively with these still deadly diseases. Therefore, further studies to look for the etiology and possible risk factors seem logical.

\section{REFERENCES}

1. Parkin DM, Stjernsward J, Muir CS. Estimates of the worldwide frequency of 12 major cancers. Bulletin WHO 1984;62:16382.

2. Parkin DM, Bray F, Ferlay J, et al. Global cancer statistics, 2002. CA Cancer J Clin. 2005 Mar-Apr;55(2):74-108. 
3. Munoz N, Day NE. Esophageal Cancer in Schottenfeld D, Fraumeni JF (eds.): cancer epidiomology and prevention Ed 2. New York, Oxford University press, 1996:681706.

4. Parkin DM, Pisani P Ferlay J. Global cancer statistics, 1999. CA Cancer J Clin. 1999 JanFeb;49(1):33-64.

5. Lu S, Lin P, Wang G, et al. Comprehensive prevention and treatment for esophageal cancer. Chin Med $J$ (Engl). 1999 Oct;112(10):918-23.

6. Fisher S, Brady L. Esophagus. In: Perez CA, Brady LJ, eds. Principles and Practice of Radiation Oncology, Third Edition. Philadelphia, PA: Lippincott-Raven, 1998:1241-56.

7. American Cancer Society. Cancer Facts and Figures 2007. Atlanta, Ga: American Cancer Society, 2007.

8. Ghavamzadeh A, Moussavi A, Jahani M, et al. Esophageal cancer in Iran. Semin Oncol. 2001 Apr;28(2):153-7.

9. Naghavi M. Death report from 10 provinces in Iran. Tehran Ministry of Health, 2000.

10. Semnani S, Sadjadi A, Fahimi S, et al. Declining incidence of esophageal cancer in the Turkmen Plain, eastern part of the Caspian Littoral of Iran : a retrospective cancer surveillance. Cancer Detect Prev. 2006;30(1):14-9.
11. Sadjadi A, Nouraie M, Mohagheghi MA, et al. Cancer occurrence in Iran in 2002, an international perspective. Asian Pac $J$ Cancer Prev. 2005 Jul-Sep;6(3):359-63.

12. Stewart A, Stewart BW, Kleihues P. World cancer report Lyon: IARC, 2003.

13. Cheng KK, Day NE. Nutrition and esophageal cancer. Cancer Causes Control. 1996 Jan;7(1):33-40.

14. Warwick GP, Harrington JS. Some aspects of the epidemiology and etiology of cancer of esophagus with particular emphasis on Transkei, South Africa. Advances Cancer Res. 1973;17(81):229.

15. World Cancer Research Fund (WCRF) Panel. Diet, nutrition and the prevention of cancer: a global perspective. Washington, DC, USA: World Cancer Research Fund; 1997.

16. Malekzadeh R, Sotoudeh M, Derakhshan $\mathrm{MH}$, et al. Prevalence of gastric precancerous lesions in Ardabil, a high incidence province for gastric adenocarcinoma in the northwest of Iran. Journal of clinical pathology 2004 Jan;57(1):37-42.

17. Pourshams A, Saadatian-Elahi M, Nouraie $\mathrm{M}$, et al. Golestan cohort study of oesophageal cancer: feasibility and first results. Br J Cancer. 2005 Jan;92(1):176-81. 